\title{
HABITAR A CIDADE: ANÁLISE DE SERVIÇOS RESIDENCIAIS TERAPÊUTICOS
}

\author{
Maria Inês Badaró Moreira \\ Faculdade de Saúde e Meio Ambiente (FAESA), Vitória, Brasil \\ Ângela Nobre de Andrade \\ Universidade Federal do Espírito Santo, Vitória, Brasil
}

\begin{abstract}
RESUMO: Trata de uma análise sobre o embate de pressupostos subjacentes à implantação/funcionamento e produção de sentidos dos denominados "Serviços Residenciais Terapêuticos", ressaltando o atual debate sobre o tema. Aponta como este 'dispositivo' tem se conformado em diferentes sociedades que aderiram ao movimento anti-manicomial, tendo como inspiração o trabalho de Basaglia, no sistema psiquiátrico italiano. Delineia-se a 'localização' sócio-histórica desse dispositivo, procurando associà-lo aos embates próprios às diversas realidades. A análise destaca uma relação imanente entre cultura (valores/sensibilidades predominantes nos modos existenciais societários) e duas formas antagônicas de conceber uma vida: como autopoiese, autocriação expansiva ou como conservação, sujeita a leis genéricas e transcendentes, que comportam prescrições e avaliações externas sobre a 'pertinência' do ser vivo. Estes pressupostos ontológico/epistemológicos emergem como centrais no atual debate sobre a loucura, carecendo de uma abordagem mais direta e rigorosa nos discursos/ações que sustentam a criação e funcionamento das moradias ou residências "terapêuticas".
\end{abstract}

PALAVRAS-CHAVE: Residências terapêuticas; desinstitucionalização; pressupostos em saúde.

\section{INHABITING THE CITY: \\ ANALYSIS OF THERAPEUTIC HOME SERVICES}

ABSTRACT: The paper is about the analysis on the impact of presuppositions underlying the implementation/operation and production of meanings of the so-called "Therapeutic Home Services", emphasizing present discussions on the subject. It points out how such a "arrangement" has been adjusted within different societies which have joined the anti-asylum movement, inspired on Basaglia's work within the Italian psychiatric system. While socially and historically "localizing" the arrangement, they are associated to the usual clashes of opposed realities. The analysis highlights an immanent relationship between culture (values/feelings which prevail among social ways of living) and two antagonistic forms of conceiving life: autopoiese, expansive self-creation or surviving, subject to generic and transcendental laws, which involve external prescriptions and evaluation on the "pertinence" of the living being. Such ontological/ epistemological presuppositions emerge as fundamental to the present discussion on insanity, which lacks a more direct and firmer approach in discourses/actions which support the implementation and operation of "therapeutic" homes for those who have been inpatients for an excessive period of time.

KEYWORDS: Therapeutic homes; de-institutionalization; presuppositions on health.

O movimento anti-manicomial, iniciado na década de 1960, acarretou transformações radicais na atenção à saúde mental, uma vez não se restringir à extinção dos hospitais psiquiátricos, mas à necessidade de acompanhamento àqueles que permaneceram durante anos alienados entre seus muros, afastados do convívio societário. Tais transformações, ainda em processo, exigem tanto rupturas conceituais e valorativas sobre a denominada loucura, quanto altos investimentos político/econômicos - antes praticamente inexistentes - na conformação de outras formas de cuidado e convivência com um número mundialmente expressivo dessa população existencialmente negada/excluída por uma política iatrocêntrica ${ }^{1}$ de confinamento.

Nesta perspectiva, algumas diretrizes básicas têm sido enfatizadas pela Organização Mundial de Saúde ([OMS], 2001), que estabelece como meta mundial a definitiva assis- tência na comunidade (processo gradual, porém urgente, do término da política manicomial), além da imposição, em curto prazo, do redimensionamento da estrutura de hospitais psiquiátricos ainda existentes: formação/treinamento dos profissionais visando procedimentos de reinserção social dos internos, implicando tanto na criação de outros modos de relacionamento psicossociais cotidianos como a transformação do espaço físico em centros de atenção e reabilitação. Tais diretrizes exigem que os serviços comunitários de saúde estejam equipados para proporcionar atenção de caráter geral e base local ao alcance dos pacientes e de suas famílias, provendo necessidades básicas como: admissão das crises em hospitais gerais, atenção ambulatorial, nutrição, moradia, reabilitação e apoio ocupacional, vocacional entre outros (OMS, 2001). 


\section{Pelo Mundo Afora... Loucura/Sociedade e Moradias 'dos Outros'}

A problemática 'moradia' apresenta-se premente (e plena de desafios) principalmente para aqueles que permaneceram internados por longos períodos e carregam as pesadas seqüelas deste confinamento. A implantação de residências já vem ocorrendo há alguns anos, com modalidades diversas de acordo com as diferentes culturas e realidades/valores norteadores das políticas públicas de saúde nos países.

Ao analisar esse processo no contexto europeu, Vasconcelos (2000) explicita alguns esquemas utilizados na criação de diferentes modalidades residenciais: (a) adaptação de casas internas ao ambiente hospitalar com a criação de espaços privados nas acomodações antigas; (b) reinserção comunitária através de habitação em famílias adotivas; (c) casas coletivas montadas na comunidade; (d) serviços integrados a um serviço aberto; (e) comunidades terapêuticas e outros esquemas individuais no mercado privado de moradias. O autor registra, assim, uma gama de diferentes dispositivos residenciais como estruturas individuais e coletivas, quartos de hotéis e pensões, famílias substitutivas, rearranjo na família de origem, dentre tantas outras possibilidades.

Estas modalidades de moradia também variam quanto ao modo de acompanhamento dessa população, que ocorre desde a continuidade da assistência permanente (vinte e quatro horas) até a ausência completa de qualquer supervisão direta de profissionais em saúde mental. Estas diferenças organizacionais dos serviços são norteadas pelo princípio básico de ofertar dispositivos adequados aos vários quadros de dependência ou níveis de autonomia do arcabouço institucional, considerando-se tanto os aparatos sócio/culturais (familiares e comunitários) quanto às características singulares de cada morador. Entretanto, os avanços nesse processo de reinserção estão diretamente relacionados com o embate de forças/interesses subjacentes à cultura manicomial de cada país e conseqüentes investimentos sócio-econômicos nas políticas públicas de saúde mental.

Na França, a partir de 1960, procurou-se delimitar a inclusão/expansão de leitos psiquiátricos e a reversão dos recursos para serviços extra-hospitalares como hospitaldia, oficinas protegidas e lares de acolhimento, deslocando a assistência exclusivamente hospitalar para um compartilhamento comunitário (Desviat, 1999). Esta nova modalidade de atenção foi adotada por algumas clínicas francesas como La borde, La chenais, entre outras, nas quais são criados espaços de trocas cotidianas entre internos e comunidades mais próximas. Ou seja, estas clínicas procuram funcionar como locais abertos em que a 'loucura' não é segregada, mas compartilhada através dos encontros diários sociais e/ou culturais, que, funcionando como acontecimentos, estabelecem um trânsito constante entre as pessoas, quebrando as dimensões de "fora e dentro" espaços/clínica e espaços/comunitários (cinemas, supermercados, cafés, festas, exposições, entre tantos outros) (Andrade, 2001; Goldberg, 1996).

Vasconcelos (2000) relata um programa de reinserção em moradias implantado na cidade de Aine-le-Chateau, em meados de 1980, no qual 1.195 usuários passaram a viver em famílias adotivas. Essa experiência foi analisada por Jodelet (1998), que revela tanto a permanência do estigma sobre figura do louco (medo do contágio, periculosidade) disseminada na população local, como a deficiência deste programa, que não previu a implantação de serviços e recursos no suporte ao retorno à vida social e ao trabalho.

Diversas análises têm denunciado, entretanto, que tais tentativas de transformação no sistema psiquiátrico francês foram reduzidas e marginais, prevalecendo uma assistência centralizada, basicamente hospitalar, não se notando um avanço de novas estruturas ou serviços. Segundo Barros (1994), no início da década de 1990, apesar de toda produção crítico/teórica no campo da análise institucional, o país ainda possuía um elevado número de pessoas internadas, com significativa população cronificada no interior do sistema asilar. Em 1988, encontrou-se, nas instalações dos antigos pavilhões do Hôpital Sainte-Anne, considerado por muitos um baluarte da psiquiatria francesa, “... o mesmo cheiro, os mesmos enfermos recentes misturados, os mesmos pacientes crônicos e o mesmo desarraigamento de qualquer outro hospital psiquiátrico do Primeiro ou do Terceiro Mundo de 20 anos ou de três dias atrás" (Desviat, 1999, p. 34). Em outras palavras, na perspectiva francesa, houve uma conciliação do hospital com os serviços externos, mas não se pretendeu transformar a cultura manicomial vigente (Rotelli, 1994).

Na Itália, no período de 1961 a 1972, Franco Basaglia introduziu mudanças no Hospital Psiquiátrico de Gorizia, criando o sistema de assembléias regulares com participação ativa de pacientes e equipe de trabalhadores. Tal inovação passou a produzir efeitos não somente no cotidiano interno ao hospital, mas também nos arredores e na cidade (Basaglia, 1985).

Este trabalho de 'dar voz aos internos' provocou forte polêmica na época, desencadeando reações críticas dos demais profissionais ameaçados em seus poderes/saberes psiquiátrico/institucionais, uma vez que as ações de Basaglia expandiam-se para além dos muros asilares, invadindo as demais estruturas sociais que sustentavam a prática psiquiátrica hegemônica e excludente. Esse enfrentamento culminou com o afastamento de toda a equipe em 1968, uma vez que esta se recusava a compactuar com as arbitrariedades daquele sistema que impunha isolamento e 
aniquilamento dos cidadãos denominados 'loucos'. A repercussão desse embate deu início ao movimento político de luta pela Reforma Sanitária em toda a Itália, expandindo e abrangendo as ações em saúde mental, que resultaram na desconstrução total da estrutura manicomial de Trieste, iniciada em 1971 (Basaglia, 1985).

Na análise da transformação triestina, vários autores (Barros, 1994; Rotelli, 1990) testemunham uma mudança de concepção e práticas de assistência em saúde mental, concretizadas através de uma extensa rede de atenção, que substituiu o tradicional hospital psiquiátrico por um serviço de emergência vinculado aos centros de saúde mental. Em 1987, esta rede já havia criado, no domínio residencial, 16 apartamentos públicos com dimensões e características diversas e 21 apartamentos sociais privados, para atender à clientela do antigo hospício.

De acordo com Dell' acqua (2005), a atual diversidade e qualidade dos recursos instalados em Trieste demonstram a viabilidade e importância de sistemas assistenciais promotores de autonomia e participação para todos aqueles antes confinados no isolamento do sistema asilar. Diversos profissionais operadores destas transformações passaram a ocupar postos de gestão nas políticas públicas de saúde italiana, assim como cargos de direção em diversos níveis da OMS. Atualmente, a Itália conta com quatro modalidades de serviços em saúde mental: centros comunitários; leitos em hospitais gerais; hospital-dia e residências (Piccinelli, Politi \& Barale, 2002).

Os centros comunitários de saúde mental geralmente são responsáveis pelo planejamento e coordenação das intervenções de diferentes níveis. As demandas de cuidados são avaliadas por equipes formadas por profissionais de diferentes áreas, que além de atenção e cuidados locais diretos à clientela, atuam também com visitas domiciliares. Os leitos em hospitais gerais estão voltados para situações de crise, prestando atendimento emergencial e encaminhando o paciente para o serviço mais próximo de sua residência. $O$ hospital-dia abarca o atendimento de média complexidade, que pressupõe diagnóstico e intervenções terapêuticas que requerem cuidados diários ainda intensos e constantes. Finalmente, as modalidades residenciais são estruturadas em diferentes níveis e contemplam, desde 1978, pacientes com longo tempo em estruturas psiquiátricas, sendo acompanhadas por uma equipe de supervisão. Estas moradias são instaladas em espaços urbanos e possuem características diferentes, levando-se em conta o perfil do(s) morador(es) e as instalações físicas da residência.

Levantamentos realizados pela equipe italiana de coordenação do 'Projeto de Residência' destacam a existência de 1.370 residências com 17.138 moradores. Existem aquelas voltadas para moradores com maior autonomia (125 moradias individuais, 108 com dois moradores e
100 com três moradores) e as que demandam maior assistência, possuindo maior número de moradores sempre adequado à capacidade de cada instalação (Girolamo et al., 2002).

Esses dados apontam para as conquistas do movimento anti-manicomial neste país, que, além da ruptura com a configuração de forças/interesses médico/hospitalares hegemônicas, exige políticas sócio-econômicas comprometidas com investimentos na saúde mental, disponibilizando os recursos financeiros necessários à manutenção dessa rede de ações altamente estruturada e articulada.

Na América Latina, verifica-se que, a partir de 1990, a maioria dos países $(70 \%)$ conta com políticas sociais para a saúde mental e, dentre estes, $80 \%$ têm planos nacionais públicos voltados para tal assistência. Até 1990, apenas $22 \%$ dos países possuíam uma legislação específica para a área, elevando, na última década, para $50 \%$ o total de países que estabeleceram legislações próprias. No tocante aos serviços comunitários, $30 \%$ dos países não dispõem desse tipo de assistência e, entre os demais 70\%, os dispositivos comunitários criados atendem uma parcela reduzida da população necessitada (OMS, 2001).

Esse rápido panorama internacional sobre os diversos processos de implantação e manutenção tanto de residências comunitárias quanto de outros dispositivos necessários ao desmanche manicomial, aponta para os desafios enfrentados pela maioria dos países na transformação da assistência à saúde mental. Estes desafios estão relacionados tanto a características sócio-culturais, como maior ou menor abertura da população no acolhimento à alteridade e adesão ao movimento quanto aos aspectos político-econômicos situados na configuração de forças hegemônicas em determinados países, como os poderes/saberes psiquiátricos altamente hierarquizados na França ou os interesses mercadológicos de fármacos na realidade norte-americana. Nos países do cone sul os desafios são ainda maiores, pois, acrescidos aos embates sócio-políticos, alia-se a precariedade de recursos para investimentos em políticas públicas. Entretanto, como observado, a maioria dos países tem aderido ao movimento anti-manicomial, criando legislações próprias voltadas para a transformação do sistema de saúde mental.

\section{O Brasil... 'Nossa' Loucura/Saúde}

(Ainda) Seqüestrada?

Acompanhando o movimento mundial, a partir de 1987 intensificam-se, em diversos segmentos societários brasileiros, os questionamentos ao modelo hegemônico de atenção à saúde mental, dando visibilidade pública a práticas de violência e exclusão/extermínio, até então restritas ao campo privado da psiquiatria. Nesse momento, estabeleceu-se de forma transparente a natureza do impasse existente no campo da assistência psiquiátrica no país, qual seja a evidente necessidade de superação do modelo 
asilar, de alto custo, ineficaz, iatrogênico e violador dos direitos humanos fundamentais (Ministério da Saúde [MS], 1999).

Ao longo da década de 1990, verifica-se, em vários municípios brasileiros, a crescente implantação de novos dispositivos de assistência, pautados nos serviços abertos de atenção à saúde mental com clara ênfase ao cuidado/ acolhimento em substituição à massiva internação. Tratase do início de grandes rupturas com a até então restrita (não) assistência médico/asilar, em que o louco (ou diagnosticado como tal) era um ser des-arrazoado, devendo permanecer isolado, passivo e alienado. Essa ruptura teve por fundamento a recuperação da potência da loucura (e não da doença) pela substituição da "assistência passiva" por ações efetivas, envolvendo diversos profissionais, os próprios internos e segmentos comunitários.

O Ministério da Saúde (MS), ao propor uma nova política de atendimento, salienta que o tratamento/cuidado dos problemas de relacionamentos humanos deve ocorrer na situação em que estes acontecem, qual seja na interação psicossocial dos diversos contextos comunitários. Para a efetivação desta política, os primeiros serviços criados foram os Centros de Atenção Psicossocial (CAPs): serviços substitutivos aos hospitais psiquiátricos, com manutenção de atenção diária (sem confinamento), através da assistência multiprofissional, comportando a extensão de atividades laborais em moradia, lazer e cultura (MS, 1999).

Faz-se importante salientar que a criação de uma legislação sobre a assistência em saúde mental não ocorre, no caso brasileiro, como um "adendo" a um sistema público de saúde nacional já estabelecido, uma vez que este não existia. Ao contrário, trata-se também da criação de um Sistema Único de Saúde (SUS), que traz transformações na assistência em saúde mental articuladas àquelas na assistência à saúde em geral, através de uma política pública nacional, legislada efetivamente em 1989, alicerçada por uma nova conceituação de saúde. A proposta do SUS privilegia as ações de prevenção e promoção comunitárias de saúde (incluindo a 'saúde mental') em substituição à hegemonia das práticas cotidianas curativas médico/hospitalares; sistema organizacional de saúde que estabelece as diretrizes/metas desta nova política, criando Programas nacionais de ações para atingi-las.

Resumidamente, o novo sistema sustenta-se em Unidades Básicas de Saúde (UBS), baseando-se na estratégia de Programas de Saúde da Família (PSF) como forma de viabilizar as ações prioritárias de prevenção e promoção de saúde junto à população brasileira. Prevê-se a necessidade de uma "equipe multidisciplinar mínima” em saúde para todos os municípios, sendo estabelecido pela portaria de n. 224/1992, que a composição dessa equipe deve ser definida pelas Secretarias Municipais de Saúde, de acordo com as necessidades locais. Estabelece, entretanto, uma equipe básica obrigatória a cada UBS (médico generalista, enfermeiro, auxiliares, assistente social e agentes de saúde), podendo contar com uma equipe de apoio de especialidades (médico psiquiatra, psicólogo, dentista, entre outros), integrada aos demais profissionais da Unidade. Em um ambulatório especializado, a equipe multiprofissional deve ser composta por diferentes categorias de profissionais (médico psiquiatra, médico clínico, psicólogo, enfermeiro, assistente social, terapeuta ocupacional, fonoaudiólogo, neurologista e pessoal auxiliar), cuja composição e atribuições são definidas pelo órgão gestor local (MS, 1992).

Observa-se, em vários municípios, uma orientação das Secretarias de Saúde para que todos os usuários (inclusive aqueles com 'transtornos mentais') sejam atendidos e cuidados pela equipe da UBS, evitando encaminhamentos para setores especializados. Tal diretrizé importante, pois aponta para uma outra concepção de loucura, não mais reduzida à "doença mental" e tratamento médico especializado, mas como um distúrbio/transtorno de saúde perfeitamente acolhido/passível de cuidado por aquela equipe multidisciplinar inserida na comunidade (Romanholi, 2004). Entretanto, como será retomada adiante, a liberação da loucura do iatrogênico saber médico não implica, automaticamente, em uma ruptura com posturas e fazeres iatrogênicos, travestido em 'novos' conceitos, como por exemplo 'transtorno mental grave'. Esta ruptura acontece (ou não) num embate de forças cotidiano, em que se faz necessária uma mudança absoluta dos pressupostos epistemológicos e ontológicos hegemônicos para a elaboração de uma outra conceituação de loucura e seus modos relacional-existenciais próprios (fora da 'idealizada e internalizada' normalidade), sem o estigma de doença, ameaça ao outro e/ou incapacidade própria de convívio social.

As configurações de forças produtoras de modos de subjetivação não são permanentes, mas se alteram conforme os embates político/econômicos em determinado momento sócio-histórico. Assim como houve o seqüestro da loucura, pela imposição do poder/saber médico, em doença mental e isolamento, observa-se, no contemporâneo, um movimento contra-hegemônico de sua inclusão social, através de cuidados no seio da comunidade. Entretanto, a efetivação dessas mudanças exige práticas/ações sustentadas por outros valores/concepções, que são engendradas no embate de forças cotidiano das relações, não se reduzindo a um conhecimento/consciência objetivos ou à vontade de um sujeito instituinte.

Assim, as ações em saúde mental, voltadas para uma ruptura com os modelos dominantes de subjetivação, são ainda recentes e frágeis em apoio àqueles que passaram por longas internações psiquiátricas. Estes continuam desafiados na superação das violências vivenciadas e recomposição de suas potências de agir, dificultados pelo julgamento moral desqualificante, ainda predominante 
nas concepções da população e profissionais (Corrigan \& Watson, 2002; Jodelet, 1998). Como conseqüência, estes ainda enfrentam muitas restrições e/ou cobranças ao retomar suas vidas fora dos hospitais, com poucas oportunidades para reconstruir um cotidiano digno e de qualidade que exigiria: trabalho/ofício compatível com sua potência singular, relações afetivo/sociais com familiares e/ou amigos, cuidado satisfatório com a saúde e criação de vínculos afetivos, através de bons encontros na circulação pela cidade.

Esses obstáculos para retomar uma vida social, agravados em países com políticas sociais precárias (ou inexistentes), foram constatados em pesquisa realizada com usuários de um serviço substitutivo no interior de Minas Gerais, em que todos experimentavam restrições e desafios devidos ao estigma do diagnóstico de 'louco' (Moreira \& Andrade, 2003). A partir do cotidiano desses usuários, foram analisadas as diversas formas utilizadas na busca de soluções para os desafios de sua reinserção na comunidade, uma vez que a proposta de desinstitucionalização não vinha acompanhada de meios/apoios efetivos para a concretização de uma vida cotidiana de qualidade. A contribuição do serviço substitutivo restringia-se a funcionar como intermediário e facilitador do retorno do usuário à sua comunidade e/ou familiares. Nesse sentido, ainda que os participantes apresentassem condições de criação/manutenção de relações afetivo/sociais, não encontravam espaço/acolhimento para desenvolvê-las na comunidade ou no entorno.

Estes entrevistados passaram por vários processos de internação, mas sempre em tempos restritos, retornando à família, com assistência de serviço substitutivo aberto. Se, para estes, os empecilhos foram tantos, pode-se inferir que a realidade daquele que viveu longos períodos de internação é muito mais desafiadora. Há um grande público de pessoas que foi enclausurada por vários anos ininterruptos e perderam, por completo, os vínculos familiares e as condições mínimas de uma inserção mais autônoma na comunidade: cuidados/criação de si (autopeiese), que é conquistada no cotidiano relacional de circulação pela cidade, espaço em que decisões e escolhas requeridas.

Verificou-se, através da pesquisa, que estas restrições estavam não somente, mas diretamente relacionadas às condições de miserabilidade sócio-econômica (sobrevivência precária e indigna dos "restos familiares") que, além de não favorecer, impediam a expressão da potência de ação singular parcialmente recomposta ao longo das vivências no serviço substitutivo. A "lucidez" e frustração perante tal realidade transpareciam claramente em suas demandas, como por exemplo, a insistência de um deles em retornar ao hospital (onde tinha condições mínimas de uma vida decente).

Esta realidade revela que, em seus aspectos técnico/ organizacionais, o processo de desinstitucionalização brasi- leiro não pode se restringir à facilitação ou preparo (ainda em serviços assistenciais) para a reinserção social dos exinternos. Faz-se necessária a implantação de dispositivos comunitários diversos que contemplem não somente uma permanente articulação entre os próprios serviços instaurados pelas políticas públicas de saúde, mas também entre estas e as demais políticas públicas que garantam moradia, lazer, educação, segurança, trabalho, enfim, os direitos sociais constitucionais.

A necessidade destes suportes foi reconhecida e parcialmente contemplada através da responsabilidade dos municípios pela criação de moradias destinadas a indivíduos que viveram longo período de internação. Estas são implantadas, com maior ou menor empenho, de acordo com as lutas/conquistas políticas de investimento público municipal no movimento de reformulação das diretrizes em saúde. Estas residências já vinham sendo criadas em alguns municípios antes mesmo da regulamentação em lei (aliás, conforme discutido acima, esta vem sempre $a$ posteriori sob pressão de práticas e políticas locais instauradas), conformando, atualmente, um panorama rico e diversificado de experiências brasileiras, que já permite um debruçar sobre ou esboçar algumas reflexões, ainda que iniciais, deste importante dispositivo.

\section{'Nossas' Moradias-Lares... \\ Lócus Heterônimo Extra-Hospitalar?}

No início de 1990, experiências das cidades de Campinas (SP), Ribeirão Preto (SP), Santos (SP), Rio de Janeiro (RJ) e Porto Alegre (RS) demonstraram a efetividade/necessidade de iniciativas, como criação de moradias, no processo de reinserção dos pacientes na comunidade. Essas experiências pressionaram sua regulamentação, efetivada pelo MS através da Portaria 106/2000, que introduz as residências terapêuticas no âmbito do SUS (MS, 2004).

Conforme regulamentação da Portaria, os denominados Serviços Residenciais Terapêuticos (SRT) devem ser implantados fora dos limites de qualquer unidade hospitalar (geral ou especializado), devendo abrigar, no máximo oito pessoas, acomodadas na proporção de até três por dormitório e as instalações devem ser adequadas ao número de moradores (MS, 2000). Para viabilizar essa nova política em saúde mental, o MS estabelece alguns incentivos como um teto orçamentário antecipado de $\mathrm{R} \$ 10.000,00$ para cada unidade residencial criada, destinado à equipagem da moradia (aquisição de móveis e objetos necessários). (MS, 2004). Outra medida de incentivo foi o remanejamento dos recursos, anteriormente destinados à manutenção dos leitos psiquiátricos, para a sustentação mensal dessa nova estrutura (MS, 2000). Esta última aparece como dispositivo político fundamental de incentivo à eliminação de leitos hospitalares, na medida em que estes recursos permanecem destinados aos usuários, porém não mais voltados para o asilamento. 
Ainda como medida de incentivo, o MS instituiu o Programa de Volta para Casa, que prevê um pagamento mensal de auxílio-reabilitação no valor de $\mathrm{R} \$ 240,00$, durante o período de um ano, pago diretamente ao morador. Este tem, dessa forma, liberdade para gerenciar tal benefício, podendo utilizá-lo para gastos pessoais, manutenção de pequenas despesas da casa ou outras atividades.

Cerca de 1.400 ex-internos de hospitais psiquiátricos são hoje moradores de SRT. A Coordenação Nacional de Saúde Mental assume que ainda existem 12.000 pacientes em hospitais psiquiátricos, sem vínculo familiar, que já deveriam estar inseridos nesta modalidade. Tais dados evidenciam a urgência e significativa expansão do número de residências, de modo a reduzir a segregação e aumentar a reinserção social de milhares de brasileiros (MS, 2004). De acordo com o levantamento de dados disponíveis no site oficial do MS e cartilhas informativas sobre a criação de SRT, pode-se enumerar 1.384 dispositivos residenciais implantados e cadastrados no MS pelos diversos municípios brasileiros.

Contudo é importante reafirmar e alertar que esses dispositivos não devem se configurar em mais um serviço de saúde (ainda que denominados 'terapêuticos'), mas concebidos como espaços de morar/habitar, uma vez que já existem as ações assistenciais de saúde, implantadas pelo município, para uso e referência desses moradores assim como o restante da população. Ressalta-se, assim, que a questão central é o viver na cidade ou conquistar o exercício cidadão, necessitando para tal, um espaço habitacional próprio, que se configure como um lar e não um local de tratamento (MS, 2004).

A criação e funcionamento destas residências vêm sendo amplamente discutidos no país e as moradias implantadas há mais tempo vêm servindo de suporte para aqueles municípios que almejam inaugurar dispositivos semelhantes. Entretanto, ainda são raros os estudos publicados que relatam ou avaliam tanto o alcance e possibilidades dessas residências, como os desafios enfrentados no dia-a-dia para sua manutenção.

Entre estes, encontra-se uma avaliação desenvolvida por Furtado e Pacheco (1997) sobre as moradias instaladas na cidade de Campinas-SP, consideradas as primeiras experiências específicas dessa modalidade, idealizadas para atender especificamente antigos moradores do Hospital Dr. Candido Ferreira. Quatro anos após a inauguração, os autores realizaram um estudo avaliativo dessa experiência no qual concluíram que ainda não havia sido alcançada uma inserção comunitária e dinâmica de funcionamento que prescindissem da instituição manicomial. Destacam alguns elementos que parecem ter contribuído para dificultar a conquista dessa independência: poucos moradores possuíam contato com outras pessoas da comunidade; não havia inserção no mercado de trabalho e a atividade de labor resumia-se às oficinas do Hospital Cândido Ferreira. Ainda de acordo com esta análise, não foram criados dispositivos alternativos de assistência que dessem suporte ao Projeto, uma vez que estes moradores não encontravam acolhimento/inserção nos tradicionais Serviços de Saúde já instalados (Furtado \& Pacheco, 1997).

Após mais de uma década, Araújo (2004) analisou três residências do município de Campinas, destacando as inseguranças presentes no cotidiano dessas pessoas por terem perdido certas habilidades fundamentais para a vida em comunidade. Assinala a discrepância entre o cotidiano instituído nos hospitais psiquiátricos, onde impera a rotina, dependência e submissão e as exigências cotidianas de se viver em uma residência, em que a rotina exige iniciativa e ações concretas, como responsabilidade pelos objetos pessoais, cuidados de si, organização e manutenção do funcionamento doméstico, entre outras.

Em análise mais recente, Furtado (2006) defende a consolidação desses espaços como dispositivo residencial no Brasil, com evidências consistentes de sua pertinência para a superação das condições hoje impostas aos "moradores de hospitais psiquiátricos", contemplando somente $10,8 \%$ do total necessário. Ainda que sob os orçamentos da saúde, essas residências não devem se configurar em mais um serviço de saúde, pois são importantes espaços de morar, de viver. As ações assistenciais devem ser prestadas pelos serviços de saúde do município em que estiver instalada, tornando-se a referência desse morador, assim como de qualquer outro cidadão. Ressalta-se que a questão central é o viver na comunidade, na cidade. Assim, tais residências não são precisamente serviços de saúde, mas espaços de morar, de viver, articulados à rede de atenção psicossocial de cada município (MS, 2004).

A denominação serviços residenciais terapêuticos deve, pois, ser compreendida apenas como uma terminologia capaz de colocar em destaque a resposta de moradia e de re-alocar recursos da saúde, inserindo um modelo diferenciado de serviço no âmbito do SUS. Ao passar por um serviço substitutivo assegura orçamentos da saúde para sua instalação. Por outro lado, se distanciam de um serviço de saúde na medida em que se configura como espaço de moradia, de re-construção de laços sociais perdidos nos anos de internação hospitalar.

Ao mesmo tempo em que esta denominação sustenta a possibilidade de existir dentro de um orçamento destinado para a saúde, refere-se a um modelo habitacional. Ainda que se corra o risco de ser compreendida equivocadamente como um serviço a ser prestado a um usuário, retirar deste dispositivo do âmbito do SUS é deixá-lo em um limbo de recursos. Uma vez destinados aos moradores de hospitais psiquiátricos que até aqui foram referenciados como números de leitos psiquiátricos hospitalares, a residência é mantida pelos cofres públicos com os orçamen- 
tos da saúde, advindos daqueles que mantinham os leitos hospitalares anteriores. Se tais residências estão compreendidas como parte de uma rede de serviços de atenção em saúde, devem compor um conjunto de estratégias que visam a dar suporte aos processos de desinstitucionalização em andamento no país, que objetivam a promoção de uma autonomia mínima para estas pessoas.

Uma análise sobre o cotidiano de uma 'residência terapêutica', criada para acolher "os loucos", exige que o pesquisador defina, de forma clara e rigorosa, os conceitos utilizados, uma vez que o próprio conceito de Loucura já implica em uma concepção de existência, de ser vivo, de uma vida. Tal rigor é pouco comum nos discursos psicológicos que tendem a se apropriar e fazer usos indiscriminados do campo conceitual. Entretanto, esta definição é imprescindível para situar o leitor sobre os pressupostos epistemológicos e ontológicos que fundamentam os critérios de valor adotados na avaliação ou, em outras palavras, a genealogia desse valor. Obviamente que para estes moradores, enclausurados e entorpecidos durante anos, o conceito de vida é bastante diverso do padrão estabelecido. Nesse sentido, se o objetivo das moradias for 'fazê-los viver de acordo com', já está fadado ao fracasso em sua própria emergência.

O conceito tão utilizado de autonomia não deve remeter a um ser autônomo, porque capaz de reproduzir determinado modelo e padrão de vida (adaptação social), mas à autocriação ou autopoiesis. Segundo Varela, tratase daquilo que é próprio dos sistemas naturais, qual seja de interagir consigo mesmos, autodeterminando-se e não sendo determinados extrinsecamente, orientados por modelos externos (Vechi, 2004). Nesse sentido, é fundamental uma discussão sobre o que se entende por 'inserção social' para que não se reproduza fora dos hospitais a mesma relação heterônoma e iatrogênica que se pretende combater.

Esse embate está confusamente exposto nos diversos discursos sobre a 'desospitalização', carecendo de reflexões mais claras sobre os pressupostos que sustentam as ações e análises na área que remetem, basicamente, à forma de conceber a produção de diferença ou uma vida.

\section{Moradias-Loucura: Incomodo Social ou Afirmação de “Modus Vivendi”’ Próprios?}

Para Basaglia (1982), o processo de desinstitucionalização requer, fundamentalmente, uma mudança da relação social com o fenômeno da loucura e a cidade é o melhor espaço de produção de novos sentidos para a vida, porque local de trocas, autocriação permanente advinda da diversidade de encontros; o oposto à internação que tem por única finalidade o isolamento e produção de relações dependentes de ordens externas, heterônomas. A compreensão dessa reabilitação ou viver na cidade é funda- mental, pois não se trata de uma adaptação da loucura à ordem social, uma vez que "o problema não é cura (a vida produtiva), mas a produção de vida, de sentido, de sociabilidade, a utilização das formas (dos espaços coletivos) de convivência dispersa" (Rotelli, 1990).

Para estes autores, a genealogia da 'doença loucura' está na hegemonia de uma configuração de forças imposta pelos poderes/saberes médico/estatais, já bem datados e conhecidos, e não em uma repulsa natural das sociedades, que até então viviam muito bem com os considerados comportamentos estranhos ou 'bizarros'. Fechar os manicômios e produzir uma forma de viver na cidade "não significa implantar aí mais ou menos artificialmente equipamentos e equipes extra-hospitalares" (Guattari, 1992). Mas promover espaços diversos de encontro que possa reinventar a maneira de conceber a loucura, ao mesmo tempo em que se desenvolvem outras práticas sociais com a contribuição e participação dos envolvidos e, principalmente com a comunidade. Para Torre e Amarante (2001) ao invés da cura, cede-se espaço à emancipação, mudando a natureza do ato terapêutico, a outra finalidade seria produzir autonomia, cidadania ativa, e desconstruir a relação de tutela e o lugar de objeto que captura a possibilidade de ser sujeito.

Trata-se, pois, de uma ruptura com o paradigma da clínica ou com os pressupostos ontológicos que concebem a vida a partir da estabilidade, tomando a imanente autopoiese como desvio, falta ou negatividade. E mais diretamente de um deslocamento da função desta clínica, de uma díade doença-cura para uma relação existênciacuidado. Deslocamento este que pretende uma revisão completa dos modelos clínicos anteriores, uma vez que a compreensão de uma doença leva a perseguir a cura, mas a compreensão da existência, leva a compreensão do homem em suas relações concretas, suas necessidades concretas, de uma vida concreta.

No atual debate encontram-se, também, aqueles que não rompem com tais pressupostos, mas propõem uma "clínica diferenciada ou ampliada", que abarca outros saberes/fazeres extra-clínicos, necessários à reformulação conceitual adotada sobre o que seja doença mental. De acordo com Tenório (2002), esta 'psiquiatria renovada' propõe um olhar não mais reduzido à doença, ou à sintomatologia da clínica tradicional, mas voltado para a existência da pessoa doente em sua totalidade, abarcando tanto as condições ditas objetivas de vida (moradia, trabalho, condições sócio-econômicas), quanto àquelas ditas $s u b$ jetivas (relações interpessoais, vivências internas). Nesta concepção, o espaço da cidade é representado pelos Caps ou uma ampliação dos cuidados (maior intensidade e diversidade). "Deve-se levar em conta tudo o que diga respeito à existência da pessoa doente, uma vez que a condição psicótica abarca a totalidade da experiência do sujeito... 
deslocando o processo do tratamento da figura da doença para a pessoa doente" (Tenório, 2002). Ainda segundo o autor, "as dificuldades concretas de vida acarretadas pela doença mental grave devem ser também elas objeto das ações de cuidado".

Esta afirmação remete a uma reflexão/problema: as 'dificuldades de vida' são acarretadas pela 'doença grave' ou esta foi acarretada pela violência/extermínio incididos sobre aqueles que se diferenciavam e/ou não se submetiam à imposição da racionalidade técnico/instrumental hegemônica?

Para estes autores, não há discordâncias radicais entre os pressupostos epistemológicos e ontológicos que sustentam a 'clínica ampliada', ainda presa nas categorizações duais e transcendentais (subjetivo/objetivo, interno/externo, pessoa doente/pessoa saudável), porém agora 'expandida' para a existência total do 'doente' e aqueles que afirmam uma vida como pura expansão, processo imanente de autocriação, diferenciação. "A instância criadora, portanto, sem ser externa ou transcendente ao que por ela é criado, deve ser pensada como um modo de operar que singulariza o vivo" (Eirado \& Passos, 2004).

Acima foi afirmado que os psicólogos (extensivo à grande maioria de 'especialistas em saúde') não aprenderam a 'refletir criticamente' sobre a genealogia dos conceitos, capturando/referenciando a multiplicidade do campo conceitual ao pensamento modelar hegemônico, que somente subsiste por um processo violento de abstração (grosseira e/ou ingênua) das diferenças imanentes a uma vida (Nietzsche, 1983). Apenas como ilustração final da impossibilidade de 'conciliação' entre os pressupostos desses dois modos de pensamento/ação presentes nos embates contemporâneos:

A noção de criação passa ao primeiro plano, enquanto a noção de lei ou determinação adquire um sentido novo, já que aparece como consequiência de um ato criador. Lei e regra não se impõem de fora e a priori, constrangendo ou limitando um ser que "poderia" se subtrair a elas. Ao contrário, emergem com esse ser, fazem parte de seu modus vivendi e, ao invés de o determinarem por limitação ou constrangimento, o determinam na medida em que constituem para ele um poder/fazer: território onde desenvolve suas capacidades (Eirado \& Passos, 2004).

Tenório (2002) assinala que sempre esteve na base da psiquiatria a questão problemática do agenciamento social da loucura. Quando se fala em substituição asilar, deve-se ter em mente que, há duzentos anos, a psiquiatria foi inventada e instituída como aparato social encarregado de responder ao problema da loucura. Desde então, este problema, que antes batia à porta de outras instituições sociais, passou a bater à porta da psiquiatria.

Enquanto o primeiro concebe a vida como autodeterminante de poderes/fazeres próprios e qualquer determi- nação externa é sempre um constrangimento ao vivo ou àquilo que cada ser pode singularmente, o segundo tem uma leitura inversa: essa imanente autocriação do vivo é um problema social 'per si' (loucura), uma vez não constrangida (não pode, não lhe é próprio) aos determinantes externos e cabe à psiquiatria resolver esse problema do/ no vivo'. Enquanto o primeiro aponta para a necessidade de uma transmutação dos valores/crenças sociais modelares hegemônicas (atual conformação societária), localizando-as como lócus do problema, o segundo visa uma mudança no ser vivo, porque próprio naquilo que pode em sua potência singular, visto como um problema à 'ordem social', considerada natural e, como tal, a única possível. Para este, o problema é o ser vivo não constrangido e não a ordem que impõe o constrangimento!

Estas reflexões são fundamentais para que a concepção/práxis manicomial não se perpetue nos diversos espaços, principalmente nas moradias, que se apresentam como um espaço ‘estrangeiro' e, como tal, pleno de experimentação contínua tanto para os moradores como para os profissionais. Esse experimentar algo em processo permite a abertura para novos modos existenciais e formas afirmativas de relação com a alteridade, sem necessidade de controles ou aprisionamentos. A casa pode 'se tornar' um espaço construído coletivamente, respeitando a potência singular de cada vida ali compartilhada, constituindose como "aconchego" e abertura para todos. "A vida é autopoiese, seguindo um curso ou deriva natural que deixa atrás de si territórios existenciais constituídos e tem à frente existências virtuais" (Vechi, 2004).

Entretanto, 'essa casa' somente existe inserida no projeto orçamentário do MS, configurando-se como um serviço substitutivo de saúde, como elucidado anteriormente. E a cilada se impõe neste ponto, pois se a compreendemos equivocadamente nos moldes de mais um serviço terapêutico, estamos tirando-lhe a possibilidade de se instituir como um espaço de produção de vida, de múltiplos sentidos e múltiplas possibilidades de habitar, circular, relacionar... Retomam-se os pressupostos normativos do 'ter que', constrangendo a imanente autocriação ao imperativo de leis externas instauradoras de relações heterônomas: retoma-se a reprodução iatrogênica ou o contínuo extermínio de vidas.

\section{Notas}

\footnotetext{
O conceito de iatrogenia foi introduzido no campo da saúde mental para designar o efeito dos serviços prestados, que tendem à conservação ou agravamento na denominada patologia. "Nessa noção, ainda utilizada no discurso científico atual, fatores presentes no atendimento em saúde mental são associados à produção de patologia de ordem psíquica na clientela, ou melhor, de uma patologia diferente daquela inicial que motivou a procura de tratamento." (Vechi, 2004).
} 
Moreira, M.I.B.; Andrade, Â.N. "Habitar a cidade: análise de serviços residenciais terapêuticos"

\section{Referências}

Andrade, A. N. (2001). Clinice Laborde: O exercício de práticas não excludentes. In H. Novo, L. Souza, L. \& A. N. Andrade (Eds.), Ética, cidadania e participação: Debates no campo da psicologia (pp. 81-98). Vitória, ES: Editora da Universidade Federal do Espírito Santo.

Araújo, A. (2004). Serviços residenciais terapêuticos em saúde mental: Um estudo etnográfico sobre as moradias de Campinas -SP. 2004. Tese Doutorado não-publicada, Universidade Federal do Espírito Santo, Vitória, ES.

Barros, D. D. (1994). Jardins de Abel: Desconstrução do manicômio de Trieste. São Paulo, SP: Editora da Universidade de São Paulo.

Basaglia, F. (1982). Psiquiatria alternativa: Contra o pessimismo da razão, o otimismo da prática. São Paulo, SP: Brasil Debates.

Basaglia, F. (1985). A instituição negada: Relato de um hospital psiquiátrico (3. ed.). São Paulo, SP: Graal.

Corrigan, P. W., \& Watson, A. C. (2002). Understanding the impact of stigma on people with mental illness. World Psychiatry. Official Journal of the world Psychiatric Association(WPA), 1(1), 16-20.

Dell'acqua, G. (2005). Trieste: 20 anõs despues. Retirado em 03 maio 2005, de www.triestesalutmentale.it

Desviat, M. (1999). A reforma psiquiátrica. Rio de Janeiro, RJ: Editora da Fundação Oswaldo Cruz.

Eirado, A., \& Passos, E. (2004, jan./abr.). A noção de autonomia e a dimensão do virtual. Psicologia Estudos, 9(1). Retirado de http:/ /www.scielo.br/scielo

Furtado, J. P. (2006). Avaliação da situação atual dos Serviços Residenciais Terapêuticos no SUS. Ciência, Saúde Coletiva (Rio de Janeiro), 11(3), 785-795. Retirado de http://www.scielo.br/scielo

Furtado, J. P., \& Pacheco, R. A. (1997). Moradias extra-hospitalares em Campinas: Reflexões sobre uma experiência. In A. T. Venâncio, E. M. Leal \& P. P. G. Delgado (Eds.), O campo da atenção psicossocial. Anais do I Congresso de Saúde Mental do Rio de Janeiro (pp. 85-93). Rio de Janeiro, RJ: Instituto Franco Basaglia.

Girolamo, G., Picardi, A., Micciolo, R., Falloon, I., Fioritti, A. \& Morosini, P. (2002). Residential care in Italy: National survey of non-hospital facilities. British Journal of Psychiatry, 181, 220-225.

Goldberg, J. (1996). Clínica da psicose: Um projeto na rede pública (2. ed.). Rio de Janeiro, RJ: Instituto Franco Basaglia.

Guattari, F. (1992). Caosmose: Um novo paradigma estético. Rio de Janeiro, RJ: Editora 34.

Jodelet, D. (1998). A alteridade como produto e processo psicossocial. In A Arruda (Ed.), Representando alteridade (pp. 47-67). Petrópolis, RJ: Vozes.

Ministério da Saúde. (1992). Portaria/GM no. 224 de 11 de fevereiro de 1992. Brasília, DF: Autor. Retirado em 21 mar. 2005, de http:// www.inverso.org.br/index.php/content/view/12230.html

Ministério da Saúde. (1999). Por uma política de saúde Mental. Brasília, DF: Autor.

Ministério da Saúde. (2000). Portaria/GM no. 106 de 11 de fevereiro de 2000. Brasília, DF: Autor. Retirado em 21 mar. 2005, de http://www.inverso.org.br/index.php/content/view/12230.html

Ministério da Saúde. (2004). Residências terapêuticas: Que são. Para que servem? Brasília, DF: Autor.

Moreira, M. I. B., \& Andrade, A. N. (2003, nov.). Ouvindo loucos: Construindo possibilidades de viver com autonomia. Revista Psicologia Saúde e Doença (Lisboa), 4(2).
Nietzsche, F. (1983). Genealogia da Moral: Os Pensadores. São Paulo, SP: Abril.

Organização Mundial de Saúde. (2001). Saúde mental nas Américas: Novos desafios num novo milênio. Washington, DC: Autor.

Piccinelli, M., Politi, P., \& Barale, F. (2002). Focus on psychiatry in Italy. British Journal of Psychiatry, 181, 538-544.

Romanholi, A. C. (2004). Na corda bamba: Reforma psiquiátrica e saúde mental na_atenção primária. Dissertação de Mestrado não-publicado, Universidade Federal do Espírito Santo, Vitória, ES.

Rotelli, F. (Ed.). (1990). Desinstitucionalização. São Paulo, SP: Hucitec.

Rotelli, F. (1994). Superando o manicômio: O circuito psiquiátrico de Trieste. In P. Amarante (Ed.), Psiquiatria social e reforma psiquiátrica (pp. 149-169). Rio de Janeiro, RJ: Editora da Fundação Oswaldo Cruz.

Tenório, F. (2002, jan./abr.). A reforma psiquiátrica brasileira, da década de 1980 aos dias atuais: História e conceitos. História, Ciências, Saúde Manguinhos, 19(1). Retirado de http://www. scielo.br/scielo

Torre, E. H. G., \& Amarante, P. (2001). Protagonismo e subjetividade: A construção coletiva no campo da saúde mental. Ciência, Saúde Coletiva (Rio de Janeiro), 6(1). Retirado de http://www.scielo.br/ scielo

Vasconcelos, E. M. (Ed.). (2000). Saúde mental e serviço social: $O$ desafio da subjetividade e da interdisciplinaridade. São Paulo, SP: Cortez.

Vechi, L. G. (2004). Iatrogenia e exclusão social: A loucura como objeto do discurso científico no Brasil. Estudos de Psicologia (Natal), 9(3). Retirado de http://www.scielo.br/scielo.

Maria Inês Badaró Moreira é psicóloga, mestre em Psicologia e doutoranda em Psicologia pela Universidade Federal do Espírito Santo. Professora do Curso de Psicologia da Faculdade de Saúde e Meio Ambiente (FAESA). Endereço para correspondência: Rua Julia Lacourt Pena, 161, Apto. 70, Ed. Cosmos, Jardim Camburi, Vitória, ES, 29090-010. mibadaro@intervip.com.br

Ângela Nobre de Andrade é doutora em Psicologia Clinica pela Pontifícia Universidade Católica de São Paulo. Professora do Departamento de Psicologia da Universidade Federal do Espírito Santo. anobre@terra.com.br

\section{Habitar a cidade: análise de serviços residenciais terapêuticos}

Maria Inês Badaró Moreira \& Ângela Nobre de Andrade Recebido: 15/05/2007

$1^{\text {a }}$ revisão: 9/07/2007

$2^{\text {a }}$ revisão: 5/09/2007

Aceite final: 12/09/2007 